\title{
Beyond Vocabulary: Exploring Cross-Disciplinary Academic-Language Proficiency and Its Association With Reading Comprehension
}

\section{Citation}

Uccelli, Paola, Emily Phillips Galloway, Christopher D. Barr, Alejandra Meneses, and Christina L. Dobbs. 2015. Beyond Vocabulary: Exploring Cross-Disciplinary Academic-Language Proficiency and Its Association With Reading Comprehension." Reading Research Quarterly 50(3): 337-356. doi:10.1002/rrq.104

\section{Published Version}

doi:10.1002/rrq.104

\section{Permanent link}

http://nrs.harvard.edu/urn-3:HUL.InstRepos:17116368

\section{Terms of Use}

This article was downloaded from Harvard University's DASH repository, and is made available under the terms and conditions applicable to Open Access Policy Articles, as set forth at http:// nrs.harvard.edu/urn-3:HUL.InstRepos:dash.current.terms-of-use\#OAP

\section{Share Your Story}

The Harvard community has made this article openly available.

Please share how this access benefits you. Submit a story.

Accessibility 
Reading Research Quarterly, 50(4) | in press

Beyond vocabulary: Exploring cross-disciplinary academic language proficiency and its association with reading comprehension

PaOla UCCELli

Harvard Graduate School of Education

Cambridge, MA, U.S.A.

EMILY PhILLIPS GALlOWAY

Harvard Graduate School of Education

Cambridge, MA, U.S.A.

CHRISTOPHER D. BARR

University of Houston, TIMES department

Houston, TX, U.S.A.

AleJANDRA MENESES

Pontificia Universidad Católica de Chile

Macul, Santiago, Chile

CHRISTINA L. DoBBS

Boston University

Boston, MA, U.S.A. 


\begin{abstract}
Despite a longstanding awareness of academic language as a pedagogically relevant research area, the construct of academic language proficiency, understood as a more comprehensive set of skills than just academic vocabulary, has remained vaguely specified. In this study, we explore a more inclusive operationalization of an academic language proficiency construct, Core Academic Language Skills (CALS). CALS refers to a constellation of high-utility language skills hypothesized to support reading comprehension across school content areas. Using the CALS-I, a theoretically grounded and psychometrically robust innovative instrument, we first examined the variability in students' CALS by grade, English proficiency designation, and socioeconomic status (SES). Then, we examined the contribution of CALS to reading comprehension using academic vocabulary knowledge, word reading fluency, and sociodemographic factors as covariates. A linguistically and socioeconomically diverse crosssectional sample of 218 students (grades 4-6) participated in four assessments: the CALS-I, a standardized reading comprehension assessment (GMRT), an academic vocabulary test (VAT), and a word reading fluency test (TOSWRF). GLM analysis of variance revealed that CALS differed significantly by grade, English proficiency designation, and SES, with students in higher grades, English proficient students, and those from higher SES backgrounds displaying higher scores, on average. Hierarchical multiple regression analyses identified CALS as an independent predictor of reading comprehension, even after controlling for academic vocabulary knowledge, word reading fluency, and socio-demographic factors. By specifying a set of language skills associated with reading comprehension, this study advances our understanding of schoolrelevant language skills, making them more visible for researchers and educators.
\end{abstract}


Beyond vocabulary: Exploring cross-disciplinary academic language proficiency and its association with reading comprehension

\section{Introduction}

Academic language proficiency, broadly understood as proficiency in "the language of schooling" (Schleppegrell, 2001, 2004), has increasingly become a topic of interest in educational circles because of its hypothesized contribution to reading comprehension and content-area achievement (Abedi \& Herman, 2010; August and Shanahan, 2006; Biancarosa \& Snow, 2006). It has become commonplace to argue that the reading comprehension difficulties documented for a large proportion of students in grades 4 and above (particularly, for students living in poverty and/or acquiring English as a second language in the U.S.) are, in large part, the result of students' challenges understanding the academic language of school texts. Moreover, students' academic language proficiency is being increasingly understood in the field as a malleable factor that can be effectively scaffolded through high-quality instruction. In fact, one of the central shifts in practice advocated by the recently and widely-adopted college and career readiness standards in the U.S. calls for "regular practice with academic language and complex texts" throughout the upper elementary and secondary school years (Common Core State Standards, National Governors Association, 2010). Paradoxically, though, an operational definition of academic language proficiency that would be sufficiently precise to inform instruction remains elusive. In the absence of a comprehensive operational construct, the field 
continues to be largely dominated by a narrow definition of academic language as academic vocabulary.

In response to various researchers' calls for more expansive definitions (Nagy \& Townsend, 2012; National Research Council, 2010; Schleppegrell, 2004; Valdés, 2004), this study examines the potential—-for both research and practice—of a more inclusive operationalization of an academic language proficiency construct (please, note that in this paper, academic language proficiency and academic language skills will be used as interchangeable terms). We refer to this operational construct as Core Academic Language Skills (CALS) (Uccelli, Barr, Dobbs, Phillips Galloway, Meneses, \& Sánchez, 2014). We define CALS as a constellation of the high-utility language skills that correspond to linguistic features prevalent in academic discourse across school content areas and that are infrequent in colloquial conversations. The CALS construct includes, for example, knowledge of logical connectives, such as nevertheless, consequently, familiarity with structures that pack dense information in texts, such as nominalizations or embedded clauses, and knowledge of structures for organizing analytic texts. To be clear, we do not focus on what some have called academic gibberish or unnecessarily dense and intricate structures that obscure communication (Krashen, 2012). Instead, we focus on high-utility academic language resources as tools for precise communication and learning across school content areas. CALS are hypothesized to support reading comprehension of academic texts and this is the main hypothesis we seek to examine in this study. Using an innovative and psychometrically robust assessment, the Core Academic Language Skills Instrument (CALS-I), we examine variability in students' CALS, as well as the relationship between CALS and reading comprehension in a linguistically and socioeconomically diverse cross-sectional sample of $4^{\text {th }}$ to $6^{\text {th }}$ grade students. In this introduction, 
we begin by reviewing current understandings of the role of language in text comprehension. Then, we review research related to academic language, and we end by presenting our proposed operational CALS construct.

\section{The role of academic language proficiency in comprehending school texts}

At least two broad lines of research inform our understanding of the role played by language knowledge in reading comprehension. On the one hand, psychological models of reading, such as the Simple View of Reading (Gough \& Tunmer, 1986) or the Reading Systems Framework (Perfetti \& Stafura, 2014), situate language knowledge as a key contributor to reading comprehension. On the other hand, language-focused research (i.e., research that understands language as inseparable from social context) has shed light on the particular demands posed by the language of school texts. For instance, functional linguistics studies and ethnographic approaches document the challenges that the language of text poses to students who have had fewer opportunities to be socialized into school-like language and literacy practices (Heath 1983; 2012; Halliday, 2004).

These psychologically focused and language-focused lines of research can be understood as complementary. However, studies that test psychological models of reading comprehension are usually not concerned with how language varies by context, and language-focused qualitative research does not typically examine quantitative associations between language and reading skills. In this study, guided by insights from these different lines of research, we seek to, first, identify cross-disciplinary language skills (i.e., CALS) that are required for participation in academic contexts; and second, test the hypothesis that CALS constitute an important predictor of individual variability in reading comprehension in grades 4 to 6 . 
Current psychological models of reading comprehension agree on the critical role played by language knowledge in reading comprehension (Gough \& Tunmer, 1986; Kintsch, 2004; Perfetti \& Stafura, 2014). The widely known Simple View of Reading model (SVR) (Gough \& Tunmer, 1986; Hoover \& Gough, 1990) posits that reading comprehension is the product of two main clusters of skills: word recognition and language comprehension skills. Developmental research guided by this model unequivocally shows that language comprehension skills become a more important predictor of reading comprehension in the upper elementary school years, when basic word recognition skills become more established and less variable across readers (Geva \& Farnia, 2012; Whitehurst \& Lonigan, 2001). Yet, to date, research inspired by the SVR model has more clearly specified the basic skills involved in word recognition (e.g., word decoding, word reading fluency) than the cluster of language proficiency skills that increasingly support text comprehension throughout development.

A recent more comprehensive proposal, the Reading Systems Framework, conceptualizes reading comprehension as the result of: (1) sources of knowledge (i.e., linguistic knowledge, orthographic knowledge, and general knowledge) that are used by (2) processes of reading (i.e., decoding, word identification, meaning retrieval, sentence parsing, inferencing, and comprehension monitoring), which take place within (3) a cognitive system with limited processing resources (Perfetti \& Stafura, 2014). Perfetti and colleagues have demonstrated that linguistic knowledge constitutes a significant contributor to reading comprehension through its influence on both word-recognition skills and meaning-making skills. However, in quantitative research that explores the contributions of language knowledge to reading comprehension, language proficiency is typically measured either as a global and underspecified construct (often measured as listening comprehension) or as a series of discrete language skills classified by 
formal linguistic levels (lexicon, morphology, syntax) (Geva \& Farnia, 2012; Hoover \& Gough, 1990; Perfetti \& Stafura, 2014). Thus, this quantitative line of research typically pays minimal attention to how language varies by context. We argue in this paper that the increasingly important role played by language skills in reading comprehension over time is in part a consequence of the particular linguistic demands posed by the school texts in the upper elementary school grades and beyond. Our approach consists of identifying the language skills called upon to understand the linguistic features that are most prevalent in school texts across content areas. In other words, instead of selecting skills only on the basis of formal linguistic levels (e.g., morphology, syntax) or without paying attention to context, we seek to identify language skills of high utility for school reading and learning. In so doing, we hope to attain a closer match between the language skills assessed and those required for successful academic reading.

\section{Language proficiency as an expanding set of situated practices}

Adopting a sociocultural pragmatics-based view of language development, we conceptualize language as inseparable from social context; language learning as contextdependent and usage-based; and, consequently, language proficiencies as the result of individuals' socialization and enculturation histories (Berman, 2004; Halliday, 2004; Ninio \& Snow,1996; Ochs, 1993; Ravid \& Tolchinsky, 2002; Snow \& Uccelli, 2009). Thus, we regard language learners as social agents who gradually master certain language resources to accomplish particular purposes by participating in particular practices and contexts (Biber, Conrad, \& Reppen, 1998; Halliday, 2004; Taylor \& Geranpayeh, 2011; van Lier \& Walqui, 2012). Sociocultural research approaches that contrasts home and school language and literacy practices have revealed that speakers are successfully enculturated into the language of face-to- 
face interaction of their respective communities (e.g., colloquial conversations with peers, interactions through social media); yet, these out-of-school practices are not always aligned with the language and literacy practices of school (e.g., the language of argumentation, the language of written informational discourse). As a consequence, many colloquially fluent students may not have been granted sufficient opportunities to be socialized into academic language and literacy practices either at home or at school (Cazden, 2002; Fang, 2006; Heath, 1983, 2012; Moje, Dillon, \& O’Brien, 2000). A few detailed case studies reveal the struggles faced by many upper elementary and middle school readers when confronted with the specialized features of the language of school text (Fang, 2012; Fang \& Schleppegrell, 2008; Wong-Fillmore \& Fillmore, 2012).

Prior studies have repeatedly shown that after the early elementary school grades, language skills become the primary source of variability in predicting reading comprehension for native English speakers and English learners, and across socio-economic levels (Dickinson \& Tabors, 2002; Lesaux, 2006). While these language skills have remained imprecisely defined, a few studies suggest that in addition to vocabulary knowledge, morphological and syntactic skills are also predictors of reading comprehension in both native English speakers and English learners (Farnia \& Geva, 2013; Kieffer \& Lesaux, 2008; Mancilla-Martinez \& Lesaux, 2011). The available ethnographic and quantitative research findings point to students from minoritized linguistic communities and from high needs environments as particularly likely to experience a larger distance between the ways language is used outside of school and the ways it is used in school texts (Heath, 2012; Wong-Fillmore \& Fillmore, 2012; Mancilla-Martinez \& Lesaux, 2010; Reardon, Valentino, \& Shores, 2012). Given that academic language skills are often transparent to teachers, assumed to be known by students, and rarely explicitly attended to 
through instruction, our work is motivated by the need to make these skills visible for educators and researchers.

\section{Advancing theory and research on academic language proficiency}

We are certainly not the first to propose a construct of academic language proficiency. More than thirty years ago, Jim Cummins raised awareness of the conceptual distinction between two components of language proficiency: BICS (Basic Interpersonal Communicative Skills) or everyday colloquial language proficiency; and CALP (Cognitive Academic Language Proficiency), which refers to "students' ability to understand and express...concepts and ideas that are relevant to success in schools" (Cummins, 2008, p. 487). Cummins' work, which focused on students learning a second language at school, identified academic language as challenging to learn in spite of students' mastery of everyday face-to-face conversational language (Cummins, 1979, 1981, 2000, 2001). To define academic language proficiency, Cummins - like several other researchers - pointed to the contexts in which academic language is used (Snow \& Uccelli, 2009). While specifying its contexts of use has been effective in attracting attention to academic language, this approach is limited by its inability to specify the precise language skills that require attention in classroom instruction, assessment, or future research.

Often, academic language skills have been narrowly operationalized as vocabulary. For example, during the last decades, a productive line of intervention studies has centered on academic vocabulary instruction as a central mechanism to improve upper elementary and middle school students' reading comprehension (Deshler, Palincsar, Biancarosa, \& Nair, 2007; Kieffer, \& Lesaux, 2007; Proctor et al., 2011). This focus on vocabulary in educational research 
has been partially motivated by extensive developmental research that documents the substantial individual variability in vocabulary knowledge and its significant contribution to reading comprehension (Nation \& Snowling, 2004; Ouelette, 2006). Despite this robust evidence from developmental studies, many vocabulary-focused interventions have evidenced significant growth in vocabulary knowledge, yet only modest gains in reading comprehension (Deshler et al., 2007; Elleman, Lindo, Morphy, \& Compton, 2009; Proctor et al., 2011). The discrepancy between developmental and intervention studies may not be surprising if we understand measures of vocabulary knowledge in developmental studies as indicators of the wider set of language skills (i.e., skill in packing dense information, connecting ideas, organizing discourse), which individuals develop in synchrony as they use language for real purposes. Among many plausible explanations for the less than satisfactory results of vocabulary-focused interventions, one possibility is that an exclusive focus on vocabulary might fail to target additional academic language skills that are also critical for text comprehension. In this study, without questioning the importance of vocabulary, we join other researchers in arguing for a broader construct of academic language proficiency in which vocabulary knowledge is one component of a more comprehensive constellation of skills (Nagy \& Townsend, 2012; National Research Council, 2010; Schleppegrell, 2004; Valdés, 2004).

Our work departs from prior and current initiatives in two additional ways: instead of conducting textual analysis, we seek to directly measure skills; and, instead of disciplinespecific skills, we focus on cross-disciplinary skills. Using textual analysis of the extended writing produced by students, a recent line of developmental linguistics has documented substantial growth in pre-adolescents' and adolescents' school-relevant language skills (e.g., Berman \& Ravid, 2009; Derewianka, 2003). The assessment tool presented in this paper will 
complement this line of inquiry by enabling the generation of inferences about students' abilities in a pre-specified set of academic language skills. Second, a few ongoing efforts are making substantial progress in assessing discipline-specific academic language skills mostly directed to support English learners' content area learning (Bailey, 2007; WIDA, n.d.). Our research focuses, instead, on cross-disciplinary skills --i.e., language skills called upon to participate in the prevalent language forms and functions that cut across academic discourses from different content areas (Bailey, 2007). Instead of focusing on English learners exclusively, we anticipate CALS-I to be relevant to capture variability within and between groups of bilingual or monolingual students. Despite the ubiquitous acknowledgement that English learner designation is typically conflated with socio-economic status in the U.S., very minimal research so far has explored the independent contribution of each of these factors to school relevant language and reading skills (Mancilla-Martinez \& Lesaux, 2010). While previous studies have examined the contribution of discrete language skills (e.g., morphology, syntax) to reading comprehension, in this study we identified and measured a more inclusive and school-relevant set of language skills. Furthermore, we examined the contribution of CALS to reading comprehension above and beyond the contribution of students' word reading fluency, academic vocabulary knowledge, socio-economic status, and English proficiency designation.

\section{A cross-disciplinary academic language proficiency construct: Converging lines of research}

The task of identifying a comprehensive subset of the language skills that support upper elementary and middle school readers in accessing texts across content areas is, however, not trivial. To formulate our operational construct, we embarked first on a thorough synthesis of theoretical and empirical research from various functional linguistics traditions that focused on: (a) profiling the linguistic features prevalent in academic texts produced by experts across 
disciplines (e.g., Biber \& Reppen, 2002; Chafe \& Danielewicz, 1987; Hyland, 2004; Halliday \& Martin, 1993; Swales, 1990); (b) identifying school-relevant language skills that display developmental progress during the upper elementary and middle school years (e.g., Bailey, 2007; Benelli, Belacchi, Gini, \& Lucangeli, 2006; Berman, 2004; Berman \& Ravid, 2009; Berman \& Verhoeven, 2002; Christie \& Derewianka, 2008; Derewianka, 2003; Nippold, 2007; Ravid \& Tolchinsky, 2002; Schleppegrell, 1998); and (c) examining the language demands of educational standards, school texts, and achievement tests in U.S. schools (Bailey, 2007; Butler, Bailey, Stevens, Huang \& Lord, 2004; Schleppegrell, 2001, 2004).

First, based on our review of studies in systemic functional linguistics, corpus linguistics, and other branches of functional linguistics, we generated an inventory of cross-disciplinary features prevalent in experts' academic discourse (for a review, see Snow \& Uccelli, 2009). Second, in studies focused on oral and written texts produced by upper elementary and middle school writers, we found evidence that pointed to a developmental progression of crossdisciplinary linguistic features closely related to those documented in experts' discourse. These studies have documented, for instance, developmental shifts in the degree of lexical precision, morpho-syntactic complexity, use of academic connectives, and organization of genre-specific elements in students' expository discourse (Berman and Ravid, 2009; Derewianka, 2003; Nippold, 2007; Ravid \& Tolchinsky, 2002). Finally, recent research on the language demands of school points to cross-discipline academic language proficiency as a promising construct to be investigated. In her analysis of classroom discourse, textbooks, assessments, and educational standards in U.S. classrooms, Bailey documents "remarkable similarities across disciplinary discourses" during the middle school years (Bailey, 2007, p. 10). Definitions, explanations, descriptions, arguments, and debates, have been described as ubiquitous text types that draw 
from a common linguistic repertoire across content areas (Bailey, 2007; Butler, Bailey, Stevens, Huang \& Lord, 2004). Although motivated by different research objectives, all these lines of research converge in pointing to overlapping sets of school-relevant linguistic features prevalently deployed across content areas.

\section{Overview of the study}

This study uses an innovative operational construct (i.e., CALS) and a recently developed instrument, the Core Academic Language Skills-Instrument (Uccelli et al., 2014) to investigate pre-adolescents' cross-disciplinary academic language skills in a cross-sectional sample of $2184^{\text {th }}$-to- $6^{\text {th }}$-grade students that included students designated by the school as English proficient (EP), Former English Language Leaners/ Formerly Limited English Proficient (FELL/FLEP), or English Language Learners (ELLs) from various socio-economic backgrounds. Two specific research questions guided our study:

1. Do $4^{\text {th }}$ - to $6^{\text {th }}$-grade students' core academic language skills --as measured the CALS-I-- vary by students' grade, English proficiency designation, or socioeconomic status?

2. Controlling for socio-demographic characteristics, word reading fluency, and academic vocabulary knowledge, are $4^{\text {th }}$ - to $6^{\text {th }}$-grade students' cross-disciplinary academic language skills -as assessed by the CALS-I-- predictive of students' standardized reading comprehension scores?

Drawing from empirical findings that have revealed considerable individual variability, as well as notable developmental trends, in vocabulary and other language areas throughout the upper primary school and middle school years in both bilingual and 
monolingual students, we hypothesized that the CALS-I task scores would capture individual variability in core academic language skills within and across grades. We anticipated that students in higher grades would achieve higher scores than those in lower grades and that English proficient students would score higher than English learners. Further, on the basis of well-documented contributions of socio-demographic characteristics (i.e., grade, SES, language proficiency), reading fluency, and academic vocabulary knowledge to reading comprehension, we anticipated all these covariates to be significant predictors of reading comprehension. Our goal was to control for all these factors to investigate the additional independent contribution of CALS-I scores to reading comprehension. As an alternative hypothesis, CALS-I scores might not capture sufficient individual variability to be a significant predictor. For instance, participants might have mastered all the language skills tested. Moreover, given that vocabulary knowledge is positioned as a critical contributor to reading comprehension (Perfetti \& Stafura, 2014), CALS-I scores might still be predictive, yet might not offer any unique contribution beyond the explanatory power of vocabulary knowledge.

\section{The proposed construct: Core Academic Language Skills (CALS)}

Informed by the research synthesis described above, we defined CALS as a constellation of the high-utility language skills that correspond to linguistic features prevalent in academic discourse across school content areas and that are infrequent in colloquial conversations. Then, guided by an integration of the empirical findings from different lines of research, we generated a hypothetical developmental map and designed a battery of CALS tasks. We also consulted lexical databases that document the frequency of particular words in academic texts used in different school grades (Zeno, Ivans, Millard, \& Duvvuri, 1995) and the grade at which students 
are expected to know particular words (Biemiller, 2010; Dale and O'Rourke, 1981). Albeit being somewhat dated, these are the most comprehensive sources available and were useful starting points to identify words documented as prevalent at different school grades. Subsequently, on the basis of a pre-pilot and pilot study of CALS tasks completed by students in the upper elementary and middle school grades (see Uccelli et al., 2014), we identified the following domains to be included in our initial operationalization of CALS (for a description of the tasks used for each domain, see Appendix 1).

Unpacking dense information | Skill in unpacking dense morpho-syntactic structures:

a. Unpacking complex words $\mid$ Skill in decomposing morphologically complex words. Morphologically complex words, in particular nominalizations, are highly prevalent in academic texts (Biber, et al., 1998; Halliday, 2004; Schleppegrell, 2004). Recent research has shown that skills in decomposing morphologically complex words contribute positively to reading comprehension in upper elementary and middle school students (Kieffer \& Lesaux, 2007, 2010).

b. Unpacking complex sentences $\mid$ Skill in understanding complex syntax. Denser syntactic structures, such as center-embedded clauses, are widely used in academic texts (Halliday, 2004; Schleppegrell, 2004). Some evidence suggests that later syntactic skills positively contribute to reading comprehension in children, adolescents, and adults (e.g., Mokhtari \& Thompson, 2006; Nation \& Snowling, 2000; Taylor, Greenberg, Laures-Gore, \& Wise, 2011).

Connecting ideas logically | Skill in understanding school-relevant connectives and discourse markers. Logical relations and discourse transitions are signaled in 
academic texts through explicit and precise markers (e.g., although, in other words) (Hyland, 2004). Although not without some controversy, several studies have provided evidence to suggest that discourse markers affect online processing, text memory, and learning from academic text (Hyönä \& Lorch, 2004; Meyer \& Poon, 2001; Meyer \& Rice, 1982).

Tracking participants and themes $\mid$ Skill in anaphoric resolution. Anaphors, i.e., words or phrases appearing in a text that refer to a prior participant or idea, can be interpreted as instructions to the reader/listener to link a previous idea with an element in the text (Givón, 1992). Whereas concrete anaphoric elements are ubiquitous in colloquial language (e.g., she refers to Mary), one type of anaphor, conceptual anaphora, is particularly characteristic of academic text. Conceptual anaphors have been estimated to account for approximately $20 \%$ of all anaphoric references in academic texts (Biber, et al., 1998). Conceptual anaphora consists of a demonstrative determiner (e.g., this) with or without a hypernoun, i.e., a noun that encapsulates meanings expressed in prior discourse (e.g., The evaporation of water occurs due to rising temperatures. This process...) (Flowerdew, 2003; Hunston \& Francis, 2000). Recent research suggests that skill in resolving conceptual anaphora is positively associated with reading comprehension for upper elementary school students (Sánchez \& García, 2009).

Organizing analytic texts $\mid$ Skill in argumentative text organization. In contrast to narrative organization skill which is well-achieved by age 9 to 10 , knowledge of how to structure expository discourse constitutes a later development that seems to consolidate only around high school age (Berman \& Nir-Sagiv, 2007). Skills in 
structuring narratives have been found to contribute to reading comprehension during the primary school years, when children read mostly narrative texts (Oakhill \& Cain, 2000). However, in the upper elementary and middle grades and above students need knowledge of additional text organization structures. Given the argumentative nature of academic language (Rex, Thomas, \& Engel, 2010; Toulmin, 1958), we focus on skills in structuring argumentative texts (i.e., thesis, arguments, examples, conclusion) as potential contributors to reading comprehension during these years. Recognizing academic register | Skill in identifying academic register. As a more exploratory and integrative task, we hypothesized that register recognition skills, i.e., students' skill in identifying more academic forms of discourse in comparison to more colloquial alternatives, may also play a role in academic reading skill. So far, we have operationalized this domain as the recognition of academic definitions. (See Appendix 1 for more details).

Rather than an exhaustive set of skills, we conceive of this set as an initial core selection to begin to delineate an operational construct of CALS. To our knowledge this is the first study to examine the contribution of a comprehensive set of cross-disciplinary academic language skills to text comprehension, above and beyond the contribution of word reading fluency, academic vocabulary knowledge, and students' socio-demographic characteristics.

\section{Methods}

\section{Participants}

A total of 218 students -distributed similarly across grades 4, 5, and 6-- participated in this study (Table 1). Students attended an urban public school in the Northeastern U.S. and were assessed 
towards the end of the school year as part of their regular school activities by three trained research assistants. The sample consisted of almost equal proportions of males and females (49\%). The majority of the sample came from homes with low socio-economic status (SES) as indexed by the eligibility for free/reduced price lunch at school. A total of 141 students (65\%) qualified for free/reduced price lunch. A total of 109 students in the sample were English Proficient (EP), while the other 109 had a current or former designation as English Language Learners (ELL). The ELL designation refers to students whose emerging English proficiency is not yet at the level expected by the district to perform ordinary classwork in English (the language of instruction) without language services. The Former English Language Learner/Former English Limited Proficient designation (FELL or FLEP) refers to former ELLs, who in the last two years have met the district's English proficiency criteria. Out of the total sample, $22 \%$ of students were designated as current ELLs and $28 \%$ of students were designated as FELL (or FLEP) by the school district.

Despite the equal distribution of students into ELL/FELL vs. EP groups, the majority of the students (83\%) had only English listed as their home language in the school official records. A home language different than English was registered for 25 students with an ELL designation; for 14 students with a FELL designation; and for 2 students classified as English proficient. The two EP students reported Vietnamese as their home language. According to school records, 21 students reported Spanish as their home language; three students reported Arabic; two students reported Haitian Creole; and ten students reported other distinct languages as home language. School records also indicated that students' ethnicity was predominantly Latino/Hispanic (41\%), followed by almost a third of African American students (30\%), and a smaller proportion of 
White students (19\%). Finally, less than a third of the students were identified to receive Special Education services by the school.

INSERT TABLE 1

\section{Measures}

As part of this study, four assessments were administered:

Core Academic Language Skills-Instrument (CALS-I): a 45-minute group-administered research instrument designed to assess CALS. The research-based CALS-I used in the present study was the result of a process that included expert linguists, psychologists, psychometricians, and educators and which unfolded in the following sequence: a Task Design Phase and Pre-Pilot Study, a Pilot Study I and an Expert Review Panel (for more information see Uccelli et al., 2014). The CALS-I form administered in this study included 36 items grouped into six tasks (See Appendix 1 for a detailed description). The items that were not scored dichotomously as correct/incorrect were rescaled to be between 0 and 1 , so that all items were equally weighted in estimating the total score. Confirming prior results (Uccelli et al., 2014), a confirmatory factor model fitting CALS-I items to a single factor produced good model fit offering evidence of unidimensionality $(\mathrm{RMSEA}=.06, \mathrm{CFI}=.95$, and $\mathrm{TLI}=.94)$. Reliability evidence was robust (.93 as indexed by coefficient alpha and .90 by split half reliability). The CALS-I raw scores ranged from 0 to 36. Using Rasch IRT analysis, factor scores were generated for the CALS-I.

Gates-MacGinitie Reading Test (GMRT): a widely used standardized group-administered reading comprehension test vertically equated to allow comparison across grades (MacGinitie, MacGinitie, Maria, \& Dreyer, 2000). The publisher reports Kuder-Richardson Formula 20 reliability coefficients of 0.90 to 0.92 , as well as robust validity evidence. Extended Scale Scores (ESS) were used for the present analysis. The ESS scale measures reading achievement 
in equal units, so that the same difference in units (i.e., a difference of 25 points) means the same all along the scale. For the GMRT reading comprehension subtest, an ESS of 500 indicates average performance at the beginning of $5^{\text {th }}$ grade, and an ESS of 525 indicates average performance at the beginning of $6^{\text {th }}$ grade (MacGinitie et al., 2000).

Vocabulary Association Test (VAT): a group-administered test of depth of academic vocabulary knowledge for upper elementary and middle school students designed by Lesaux and colleagues based on the work by Schoon \& Verhallen (1998) (as cited by Carlo et al., 2004) (Lesaux, Kieffer, Faller, \& Kelley, 2010). The test includes 15 items and all target words are drawn from the academic word list (Coxhead, 2000). Each item includes a target word in the center of a box, surrounded by six other words, three of which are immutably associated with the target word, and three of which are only circumstantially related to the target word. For example, effect has immutable associations with cause, consequence, and result, yet only circumstantial associations with negative, policy, and people. Students are instructed to "draw a line to the three words that always go with the word in the middle or are most related to the word in the middle.” (Lesaux et al., 2010). The estimate of internal consistency for this task in a prior study was adequate (Cronbach's alpha $=.78$ ). Prior studies have also provided convergent and divergent validity evidence (Carlo et al., 2004; Lesaux, et al., 2010; Schoonen \& Verhallen, 1998, cited in Carlo et al., 2004). Of special interest is the strong correlation $(\mathrm{r}=0.67)$ between this measure and a standardized measure of vocabulary knowledge (Stanford Achievement Test-10th Edition: Reading Vocabulary Subtest) reported by Lesaux and colleagues in their sample of $6^{\text {th }}$-grade English learners and English proficient students. 
Test of Silent Word Reading Fluency (TOSWRF): a group-administered test of silent word reading fluency that measures the ability to recognize printed words accurately and efficiently in students in grades 1 and above (Mather, Hammill, Allen, \& Roberts, 2004). The TOSWRF is comprised of rows of words with no spaces between them that are ordered by reading difficulty (e.g., dimhowfigblue). Students were given 3 minutes to draw a line between the boundaries of as many words as they could (e.g., dim/how/fig/blue). The TOSWRF standard scores, based on a mean of 100 with a standard deviation of 15 , were used in this analysis.

\section{Analytic plan}

Drawing from prior analyses of upper elementary and middle school students' CALS-I data, the CALS-I scores were operationalized as a unitary construct (Uccelli et al., 2014). Descriptive statistics by grade and by English proficiency designation (ELL, FELL, and EP) were generated for the CALS-I scores, as well as for the word reading fluency measure (TOSWRF), academic vocabulary knowledge test (VAT) and for the reading comprehension assessment (standardized Gates-MacGinitie Reading Test, GMRT). To address our first research question, we conducted GLM analysis with grade (three levels), English proficiency designation (three levels), and SES (two levels) as between-subject factors and CALS-I scores as dependent variable. To address our second research question, we first conducted pairwise correlational analyses to explore associations between the Gates-MacGinitie reading comprehension scores, CALS-I scores, word reading fluency, academic vocabulary knowledge, and the sociodemographic variables. Finally, to assess the predictability of the CALS-I scores, hierarchical regression analyses were conducted, with reading comprehension as the 
outcome variable and socio-demographic characteristics, reading fluency, and academic vocabulary knowledge as covariates. The effects of socio-demographic characteristics were explored first by entering socio-demographic variables (grade, English Proficiency Designation, SES) as covariates in successive steps. Following a stepwise approach, subsequently, word reading fluency and academic vocabulary knowledge were entered as covariates and, finally, CALS-I scores were entered as the question predictor.

\section{Results}

\section{Descriptive Statistics}

Table 2 (shadowed lines) displays students' means and standard deviations by grade and by English proficiency designation for students' CALS (CALS-I), reading comprehension (GMRT), academic vocabulary knowledge (VAT) and word reading fluency (TOSWRF). CALSI scores displayed evidence of across-grade as well as within-grade variability. As displayed in Table 2, the mean CALS-I total scores per grade revealed that student performances improved across grades, and more markedly in grade 6 . The CALS-I mean scores per grade was lowest in $4^{\text {th }}$ grade, with a mean of $.03(\mathrm{SD}=1.61)($ mean raw score $=18.79, \mathrm{SD}=9.98$; mean percent correct score $=.52, \mathrm{SD}=.28$ ), and progressively higher across grades, with the highest mean of $.71(\mathrm{SD}=1.67)($ mean raw score $=22.54, \mathrm{SD}=9.49$; mean percent correct score $=.63, \mathrm{SD}=.26$. displayed by $6^{\text {th }}$ graders. In addition, these mean CALS-I scores also revealed considerable individual variability within grade. Standard deviations fluctuated from 1.62 to 1.67 across grades, displaying approximately normal distributions in each grade with a wide range of scores. Similar trends were observed for academic vocabulary knowledge. For reading comprehension and reading fluency, the upward trend in $6^{\text {th }}$ grade is clear, yet unexpectedly the 5 th grade subgroup displayed the lowest mean word reading fluency score and mean reading 
comprehension score in the full sample. Furthermore, considering that an ESS of 500 indicates average performance at the beginning of $5^{\text {th }}$ grade, and an ESS of 525 indicates average performance at the beginning of $6^{\text {th }}$ grade, the GMRT mean ESS per grade suggests that this is overall a somewhat low performing sample.

INSERT TABLE 2

When the descriptive statistics were disaggregated by English proficiency designation (see Table 2), the general trend for CALS-I scores and all other measures was for students with an ELL designation to display lower scores than either FELL or EP students, within grade. This was not the case for $5^{\text {th }}$ graders, though. Reading fluency is the area in which this EP group of $5^{\text {th }}$ graders displays almost the lowest scores of the full sample, only 0.2 points above that of the $5^{\text {th }}$ grade ELL group and even lower than the $4^{\text {th }}$ grade ELL group. With the socio-demographic and assessment data available we could not detect a pattern that would explain the somewhat unusually low scores in word reading fluency and reading comprehension for EP $5^{\text {th }}$ graders.

Research Question 1: Variability in CALS-I scores by grade, English proficiency designation and SES status

To answer our first research question, we conducted a GLM analysis of variance with CALS-I scores as dependent variable and three between-subject factors: grade (three levels), English proficiency designation (three levels), and SES (two levels). Results revealed that CALS-I scores differed significantly as a function of each of these three socio-demographic factors (grade: $\mathrm{F}(2,212)=5.42, \mathrm{p}<.005$; English proficiency designation: $\mathrm{F}(2,212)=7.83$, $\mathrm{p}<.0005$; and SES: $\mathrm{F}(1,212)=20.51, \mathrm{p}<.0001)$. Post-hoc Scheffe tests revealed statistically significant differences between the CALS-I scores of students in grade $6(\mathrm{M}=0.71 ; \mathrm{SD}=1.67)$ compared to students in grades 4 or 5 . However, even though $5^{\text {th }}$ graders' CALS-I scores 
$(\mathrm{M}=0.09 ; \mathrm{SD}=1.2)$ were on average higher than $4^{\text {th }}$ graders' CALS-I scores $(\mathrm{M}=0.03 ; \mathrm{SD}=1.61)$, the difference was not large enough to be significant. Post-hoc Scheffe tests revealed that students with an ELL designation displayed significantly lower CALS-I scores $(\mathrm{M}=-0.57$; $\mathrm{SD}=1.02$ ) than both students with either a FELL or an EP designation. FELL and EP students' CALS-I scores ( $\mathrm{M}=0.69 ; \mathrm{SD}=1.53$; and $\mathrm{M}=0.46 ; \mathrm{SD}=1.6$, respectively), however, were not statistically significant from one another. In fact, as can be observed in Table 3, in grades 4 and 5, FELL students outperformed their EP peers. CALS-I scores also varied significantly by SES. In the full sample, the mean CALS-I score for students from higher SES backgrounds was $\mathrm{M}=0.89(\mathrm{SD}=1.65)$, whereas the mean CALS-I score for students from lower SES backgrounds was only $\mathrm{M}=-0.03(\mathrm{SD}=1.41)$.

We further explored differences in CALS-I scores by SES within each of the English proficiency designation groups. As would be expected, differences by SES were not significant for students classified as English language learners. Not surprisingly, all these students regardless of SES displayed, on average, the lowest CALS-I scores in our sample. Interestingly, though, CALS-I scores differed significantly by SES both within the group of FELL students and within the group of EP students (FELL: $F(1,61)=5.68$, $p<.05$; EP: $F(1,106)=10.21, p<.00$ ). As can be observed in Figure 1, on average students from higher SES performed significantly higher than their peers from lower socio-economic environments not only within the group of students formerly classified as English learners, but also within the group of English proficient students.

- INSERT FIGURE 1

Research Question 2: CALS-I scores as a predictor of reading comprehension

After examining correlations between the CALS-I and all other variables (see Table 3), we selected all variables that displayed significant associations with reading comprehension 
scores for the hierarchical regression analyses. First, we explored the impact of sociodemographic factors on reading comprehension: grade, gender, SES, and language status. Grade and gender were found not to be significant predictors; however, grade was kept in all models to account for maturation and schooling experience. We entered English proficiency designation first, and then SES. As can be observed in Model 1 (see Table 4), after controlling for grade, English proficiency designation (coded as $\mathrm{EL}=2 ; \mathrm{FELL}=1 ; \mathrm{EP}=0$ ) was found to be a significant predictor.

INSERT TABLE 3

Model 1 accounted for $9 \%$ variance in reading comprehension $(=0.09), 8 \%$ of which was added when English proficiency was added to a model that had grade as the sole non-significant predictor. In Model 2, we entered socio-economic status (coded as eligible for free/reduced lunch $=1$; not eligible for free/reduced lunch=0), which revealed a significant negative relationship with reading comprehension, accounting for $8 \%$ of the variance $=0.08$ ). In other words, Model 2 indicates that controlling for grade and English proficiency designation, students from low SES backgrounds tended to display significantly lower reading comprehension scores than their peers from higher SES backgrounds. The inclusion of SES accounted for an additional 4\% increase in the variance explained. As a next step, we entered word reading fluency (TOWSRF) to remove the variability associated with basic word recognition skills before we explored the effect of academic language proficiency in reading comprehension. As can be observed in Model 3 (Table 4), word reading fluency (TOSWRF) explained a significant amount of variance in reading comprehension skills, accounting for an additional $26 \%$ of the variance $(=0.38)$. Not surprisingly, these results indicate that, holding all the socio-demographic characteristics constant, students with higher word reading fluency scores tended to have higher reading comprehension scores. In Model 4, academic vocabulary knowledge was entered into the 
regression. Consistently with prior research, academic vocabulary knowledge accounted for a significant portion of the variance in reading comprehension, indicating that after controlling for socio-demographic characteristics and word reading fluency, students with higher academic vocabulary knowledge tended to score higher, on average, on the reading comprehension assessment. Academic vocabulary knowledge explained an additional 9\% of the variance over the other covariates $(=0.47)$. Finally, in Model 5, CALS-I scores, our measure of academic language skill and our question predictor, was added to the model. The results of Model 5 indicate that CALS made a significant independent contribution to individual differences in reading comprehension over and above the contribution of academic vocabulary knowledge, word reading fluency, SES, English proficiency designation, and grade. Moreover, CALS-I scores accounted for an additional $12 \%$ of the variance in reading comprehension for this sample $(=0.59)$. It is interesting to note that despite the shared variance between academic vocabulary knowledge and CALS, each of them offered a significant independent contribution to reading comprehension. Notably, once academic vocabulary knowledge and CALS were added to the model, SES was no longer significant. These results suggest that after word reading fluency was controlled for, the variability in students' academic language skills (vocabulary and other related skills) captures the very pedagogically relevant skills that are typically indexed by categorical socio-demographic variables, which can only serve as imperfect proxies of language proficiency. INSERT TABLE 4

\section{Discussion}

The goal of this study was to specify and empirically assess the school-relevant language skills hypothesized to support reading comprehension during the preadolescent years. Guided by our operationalization of the CALS construct, a cross-sectional sample of 218 students from 
grades 4, 5, and 6 --from different SES backgrounds and with different English proficiency designations - were administered the CALS-I. Aligned with prior research, results revealed considerable within- and between-grade variability in students' CALS-I scores with an overall upward trend across the higher grades (Uccelli et al., 2014). This study extended prior findings in a few directions. First, confirming prior research, this study revealed that students from lower SES environments and those with a designation of English language learner (ELL) scored, on average, significantly lower than students from higher SES environments and those without an ELL designation, respectively. However, a particularly interesting finding was that, within the English proficient (EP) and FELL groups, students from lower SES backgrounds displayed, on average, significantly lower CALS-I scores than their more privileged EP and FELL peers, respectively. These results highlight the relevance of the CALS construct not only for English learners, but also for students designated as English proficient and, presumably, monolingual students. Finally, CALS --as measured by the CALS-I-- was found to be a significant predictor of students' reading comprehension (as measured by the standardized GMRT), above and beyond the contribution of academic vocabulary knowledge (VAT), word reading fluency (TOSWRF), and socio-demographic characteristics. While it should be of no surprise that, analogous to academic vocabulary knowledge, a broader set of general academic language skills would be predictive of reading comprehension, the innovation of this study resides in having identified and empirically tested an initial set of high-utility cross-disciplinary academic language skills that seem to be relevant for text comprehension and, thus, worth exploring further. Below we interpret our findings in light of prior research, discuss pedagogical implications, and propose areas for further research. 
The CALS construct and the CALS Instrument: Evolving research tools

To our knowledge, the CALS-I is the first instrument that attempts to capture students' knowledge of a constellation of high-utility language skills that have been intentionally and systematically selected to be representative of skills regularly called upon for successful participation in reading academic texts across content areas. Our work has identified at least an initial repertoire of cross-disciplinary academic language skillsets associated with reading comprehension during the upper elementary and middle school years (Uccelli et al., 2014). On the basis of functional linguistics research, we have classified the skillsets examined in this study into several interrelated domains: (a) unpacking dense information (i.e., skill in unpacking morphologically complex words and complex sentences); (b) connecting ideas logically (i.e., skill in understanding school-relevant connectives and discourse markers); (c) tracking participants and themes (i.e., skill in anaphoric resolution); (d) organizing analytic texts (i.e., skill in organizing school-relevant analytic texts); (e) recognizing academic register (i.e., an integrative task that measures skill in identifying academic register). These domains are meant to offer a theoretical framework to capture important aspects of a phenomenon that in reality cannot be separated into such discrete areas. Moreover, as we emphasize throughout this article, we do not understand the empirically-tested set of skills proposed in this study as exhaustive. Instead, we consider this study as a starting point for the operationalization of a construct that needs to be explored further. Figure 2, which is intended as a visual display of the CALS construct, includes the domains that we have empirically explored in this and prior studies, as well as two additional theoretically-grounded domains that we are currently investigating: $(f)$ understanding metalinguistic vocabulary (i.e., skill in understanding academic metalinguistic vocabulary, 
namely, the particular subset of vocabulary words that refer to language or thinking processes and support text-based discussion and argumentation, such as counterargument, generalization); and $(g)$ interpreting viewpoints (i.e., skill in understanding markers of stance, in particular markers of epistemic stance or degree of certainty, such as it is possible that, undoubtedly). Elaborating further on these two latter domains goes beyond the scope of this paper, yet we mention them here as an illustration of how the CALS construct and the CALS-I constitute evolving research tools expected to be gradually refined in order to capture --ideally with increasing precision-- some critical language skills that are pedagogically relevant and lie at the center of providing equitable opportunities to learn for all students.

Within-grade and between-grade variability in cross-disciplinary academic language skills

Limited prior research has documented developmental trends in school-relevant features in upper elementary, middle, and high school students' text productions (Berman \& Ravid, 2009; Derewianka, 2003). In production studies, however, inference about ability can only be made about the linguistic features students spontaneously include in their writing, but the question of whether they might know more than what they opt to display -or can produce-- in their writing cannot be answered. Moreover, in contrast to our study, most of these studies focus on describing developmental trends in middle class populations, without special attention to individual variability in linguistically and socio-economically diverse samples.

Consistent with prior findings, CALS-I scores indicated that grade 6 students performed significantly higher than students in earlier grades. Yet, CALS-I scores did not capture between grade variability in the youngest students in the sample (grades 4 and 5). This result may be related to the idiosyncratic nature of the sample used in this study. In particular, students in grade 
5 in this study displayed literacy skills (specifically, word reading fluency and reading comprehension) that were unexpectedly lower than those of their $4^{\text {th }}$ grade peers. Alternatively, it may be the case that grade 6 marks a particularly steep developmental shift for CALS skills, perhaps as a result of the increased exposure to complex texts containing academic language that students in this grade start to experience more regularly. The cross-sectional nature of this sample, however, limits the conclusions we can draw from the between-grade variability observed.

In addition to the upward trend documented across grades, the substantial within-grade variability in CALS-I scores is particular noteworthy yet not surprising in light of prior research that has documented substantial individual differences in language development, particularly in vocabulary learning for both monolingual and bilingual students in the upper elementary and middle school years (Biemiller \& Slonim, 2001; Mancilla-Martinez \& Lesaux, 2010).For educators, this finding provides insights into the diverse levels of linguistic challenges readers in the same grade --and in the same classroom-- may face when presented with complex, gradelevel text. These results suggest that expanding the canon of academic language features that are addressed through instruction as educators attempt to build deeper knowledge of content may be necessary to adequately support students in achieving the lofty goals set by the Common Core State Standards (2010).

Beyond SES and English proficiency designations: CALS as a pedagogically-relevant predictor of reading comprehension

Interestingly, in this study the impact of the socio-demographic factors of English proficiency designation and SES status on reading comprehension became non-significant once 
academic vocabulary knowledge and CALS-I scores were added to the model. Beyond the contribution of word reading fluency, academic vocabulary and CALS seem to be among the key linguistic skills relevant for reading at school that are most influenced by these sociodemographic characteristics. These findings help to further integrate the insights from quantitative and qualitative studies that have highlighted, on the one hand, the low performance in discrete language skills and reading comprehension tests usually displayed by English learners and students from low SES environments (Farnia \& Geva, 2013; Kieffer \& Lesaux, 2010); and, on the other, the challenges documented by particular subgroups of students with the language of schooling (Heath, 1983, 2012; Cummins, 2000). By specifying an operational CALS construct, this work contributes to making the pathway from school-relevant language skills to reading comprehension visible for researchers and educators, alike. Moreover, and to some extent not surprising, CALS-I scores were found to be better predictors of reading comprehension than SES or English proficiency designation. As we know, there is considerable variability in students' skills within SES groups and within language proficiency groups (both within bilingual and monolingual students). Certainly, not all students who come from low SES environments will display low proficiency in academic ways of using language; and, conversely, not all monolingual students classified as English proficient will display high levels of academic language proficiency.

By understanding language learning and use as socially situated, these results highlight the need to understand first and second language proficiency, not as monolithic entities, but as context-dependent. More specifically, these results highlight the need to distinguish two constructs that are often discussed as one and the same: first, general language proficiency (e.g., whether in English or a second language, or both) and, second, proficiency in the ways of using 
language at school (academic language or the language of school literacy and learning). Whereas Cummins raised awareness of this distinction for bilingual learners, our results indicate that this distinction is presumably also relevant for monolingual speakers, especially for those with fewer opportunities to participate in school-like discourse exchanges, either outside or inside of school. Monolingual students --typically, automatically classified as English proficient-- might be highly fluent conversationally, yet can also be unfamiliar with more academic ways of using language. As state above, this tended to be the case, for the EP group from low SES environments in this sample.

Categorical SES and English proficiency designation variables are only imperfect proxies that typically index fewer opportunities to participate in school-relevant language and literacy practices. In contrast, CALS-I scores served as a better predictor of reading comprehension, offering evidence that directly links a pedagogically relevant and more comprehensive construct of academic language proficiency with reading comprehension. For educational purposes, a pedagogically relevant construct and instrument that make the school-relevant language skills visible for instruction and research represent an initial step towards generating empirical evidence that might support teachers in identifying language strengths and areas of vulnerability in their classrooms.

\section{Limitations of the current study and future research directions}

To conclude, adding to other well documented skills (e.g., background knowledge, motivation, strategy use, vocabulary knowledge), this study expands the range of known contributors to reading comprehension and suggests that core academic language skillsunderstood as a constellation of skills - is a relevant construct to understand students' academic 
literacy. It is important to remember, though, that this constitutes only one slice from the much larger enterprise of preparing students for the "multiple dimensions of school communication" (Valdés, Capitelli, \& Alvarez, 2011, p. 189). Here, we discuss limitations of our study and outline future directions for the exploration of school-relevant language skills.

First, one limitation of our study is the small sample of only 218 students. Caution should be exerted in drawing inferences beyond the sample. This is particularly important in light of the fact that our sample comprises a low-performing group of students, as indicated by their lower than average GMRT reading comprehension scores. Even though our sample's GMRT performance is representative of urban public schools in the region, understanding crossdisciplinary academic language development requires the inclusion of a sample with a wider range of academic literacy levels. A second limitation is the cross-sectional design. The acrossgrade trends reported here can only suggest directions for developmental research, which requires longitudinal studies. The next step in this research would entail following students longitudinally to document individual variability in developmental trajectories and in more diverse samples that ideally include the full range of potential performances.

Our results are promising but require further research in a variety of directions. In fact, the work presented here is only a fragment of our larger research enterprise, which focuses on understanding school-relevant language development in relation to skills not only in academic reading comprehension, but also academic writing, classroom discussion, and academic register awareness.

Furthermore, the tested set of skills examined in this study is not meant to be exhaustive, and certainly, needs to be expanded to consider other potentially relevant areas, such as understanding metalinguistic vocabulary or interpreting viewpoints (see Figure 2). Presently, we 
are investigating these two domains, but additional ones could still be explored. We are acutely aware of the fact that several more complex language skills involved in understanding academic texts are not measured by this instrument, e.g., the use of nominalizations to uncover agency or to create taxonomies; the realization of logical connections via nouns, verbs and prepositions instead of via explicit connectives (Fang, Lamme, \& Pringle, 2010). Informed by our work on the CALS construct, future research that seeks to specify academic language skills relevant for more advanced secondary and higher education students, as well as for younger students, could be illuminating. We also acknowledge that the reading comprehension assessment used in this study captured this ability only generally. Further examining the relationship between CALS and skills in comprehending more advanced disciplinary texts (i.e., tests that measure students' comprehension of science, social studies and humanities texts, such as the American College Test-ACT) would be insightful.

As is the case with vocabulary knowledge (Stahl \& Nagy, 2006), there is most likely a reciprocal relationship between CALS and reading comprehension, such that the more proficient a reader is in CALS, the better his or her comprehension of academic texts. Conversely, a skilled reader who can access challenging texts that contain more CALS features is afforded more opportunities to expand his or her CALS. Future studies might explore this potential bidirectional relationship further.

To be clear, we do not view academic language proficiency as the exclusive goal of later language development. Instead, during the adolescent years, progress in language abilities entails expanding one's "rhetorical flexibility," i.e., the ability to use lexico-grammatical and discourse forms appropriately and flexibly in an increasing variety of social contexts (Ferguson, 1994; Ravid \& Tolchinsky, 2002). In fact, a comprehensive assessment of later language development 
(which our CALS-I is not given its focus on school-relevant language) would also seek to index growth in other ways of using language. However, while CALS-I focuses only a subset of the wider language forms needed by adolescents to participate in a range of contexts, we opted to focus on this subset due to their centrality for academic success and presumably also for professional life and civic participation in society (LeVine, LeVine, Schnell-Anzola, Rowe, \& Dexter, 2012).

Research that examines the home and community literacies that all students bring to the classroom and the potential language and literacy practices that support CALS development in diverse learners is also needed. In the continued work to make academic language skills visible, we must also be aware of the threat posed by the deficit paradigm that would situate these skills as more valuable than the home literacy skills that learners bring. Beyond the language of school, preadolescent and adolescent students participate in many complex ways of using language (e.g., youth discourses, religious, or sports discourses) and, therefore, pedagogy needs to value, recognize and build on students' existing knowledge of outside-of-school language to scaffold the expansion of the particular repertoire relevant for learning at school (Phillips Galloway, Stude, \& Uccelli, in press).

As stated by Bailey, Burkett, \& Freeman (2008), instead of an accessible medium of instruction, the language of school is often opaque to students, while at the same time being often transparent to teachers. The CALS-I might offer a preliminary tool to make the language comprehension difficulties encountered by students salient to their instructors. In contrast to discipline-specific skills, cross-disciplinary language skills seem particularly important for pedagogy, as these are particularly invisible for content area teachers. Ideally, by identifying some of the language forms and functions that are challenging for students, educators can 
anticipate language-based difficulties in text. Such cross-disciplinary academic language consciousness might support educators in identifying instructional instances where paraphrasing, unpacking and paying explicit attention to language structures, and fostering language-conscious text-based discussions with students may open new opportunities to support students' content learning and conceptual understanding (van Lier \& Walqui, 2012; Wong-Fillmore \& Fillmore, 2012).

We could envision as a later outcome of this research line, a pedagogically informative tool that would serve to make school-relevant language skills visible to teachers and students. Instead of a tool intended to measure individual performance, a desirable scenario would be to develop a tool that offers a classroom portrait as part of a comprehensive approach to understand the linguistic composition of a class, including classroom discourse observations and data on students' voices and reflections about the language of school (Phillips Galloway et al., in press). Far from attempting to assess individual students, our goal is to develop tools to support teachers in being more attuned to the language needs of their students. Instructional initiatives informed by a precise and more comprehensive set of language skills might constitute promising next steps in this newly emerging research area. 


\section{ACKNOWLEDGMENTS}

The research reported here was supported by the Institute of Education Sciences, US Department of Education through Grant R305F100026, which was awarded to the Strategic Education Research Partnership as part of the Reading for Understanding Research Initiative. The opinions expressed are those of the authors and do not represent the views of the institute or the US Department of Education. We express our gratitude to the students and teachers who shared their valuable time and insights with us and to our numerous colleagues for their helpful comments as we conducted this work. In particular, we want to give special thanks to our colleague Emilio Sánchez from the Universidad de Salamanca, Spain, who worked closely with us during the first of the CALS-I development. Special thanks are also due to Matthew Ellinger (SERP Design Center) who generously helped us with the graphic display of the CALS construct. Finally, we want to thank the three anonymous reviewers whose encouraging and helpful feedback contributed to improving this article. 


\section{References}

Abedi, J., \& Herman, J. (2010). Assessing English language learners' opportunity to learn mathematics: Issues and limitations. Teachers College Record, 112, 723-746.

Andersen, E. S. (1996). A cross-cultural study of children's register knowledge. In D. I. Slobin, J. Gerhardt, A. Kyratzis, \& J. Guo (Eds.), Social interaction, social context, and language: Essays in honor of Susan Ervin-Tripp (pp. 125-142). Mahwah, NJ: Erlbaum.

August, D., \& Shanahan, T. (2006). Developing literacy in second language learners: Report of the National Literacy Panel on language minority and youth. Mahwah, NJ: Erlbaum.

Bailey, A. L. (2007). The Language Demands of School: Putting academic English to the test. New Haven, CT: Yale University Press.

Bailey, F., Burkett, B., \& Freeman D. (2008). The mediating role of language in teaching and learning: A classroom perspective. In B. Spolsky \& F. Hult (Eds.), The handbook of educational linguistics (pp. 606-625). Oxford, UK: Blackwell.

Benelli, B., Belacchi, C., Gini, G., \& Lucangeli, D. (2006). "To define means to say what you know about things": The development of definitional skills as metalinguistic acquisition. Journal of Child Language, 33, 71-97.

Berman, R. A. (2004). Language development across childhood and adolescence. Amsterdam: Benjamins.

Berman, R. A., \& Nir-Sagiv, B. (2007). Comparing narrative and expository text construction across adolescence: A developmental paradox. Discourse Processes, 43, 79-120. 
Berman, R. A., \& Ravid, D. (2009). Becoming a literate language user: Oral and written text construction across adolescence. In D. R. Olson, \& N. Torrance (Eds.), Cambridge handbook of literacy (pp. 92-111). Cambridge, UK: Cambridge University Press.

Berman, R. \& Verhoeven, L. (2002). Cross-linguistic perspectives on the development of textproduction abilities: Speech and writing. Written Language and Literacy, 5, 1-44.

Biancarosa, G., \& Snow, C. E. (2006). Reading Next-A vision for action and research in middle and high school literacy: A report from Carnegie Corporation of New York. Washington, DC: Alliance for Excellent Education.

Biber, D., Conrad, S., \& Cortes, V. (2004). 'If you look at...': Lexical bundles in university teaching and textbooks. Applied Linguistics, 25, 371-405.

Biber, D., Conrad, S., \& Reppen, R. (1998). Corpus Linguistics: Investigating Language Structure and Use. Cambridge, UK: Cambridge University Press.

Biber, D. and Reppen, R. (2002). What does frequency have to do with grammar teaching? Studies in Second Language Acquisition, 24, 199-208.

Biemiller, A. (2010). Words worth teaching: Closing the vocabulary gap. Columbus, $\mathrm{OH}$ : SRA/McGraw-Hill.

Biemiller, A., \& Slonim, N. (2001). Estimating root word vocabulary growth in normative and advantaged populations: Evidence for a common sequence of vocabulary acquisition. Journal of Educational Psychology, 93, 498-520.

Bishop, D. V. (2003). Test for reception of grammar: TROG-2 version 2. Pearson Assessment.

Butler, F.A., Bailey, A. L., Stevens, R., Huang, B. and Lord, C. (2004). Academic English in 5thgrade Mathematics Science, and Social Studies Textbooks. CSE report \# 642. Los 
Angeles: University of California, National Center for Research on Evaluation, Standards, and Student Testing (CRESST).

Cain, K. \& Oakhill, J. (2006). Profiles of children with specific reading comprehension difficulties. British Journal of Educational Psychology, 76, 683-696.

Carlisle, J. F. (2000). Awareness of the structure and meaning of morphologically complex words: Impact on reading. Reading and Writing, 12, 169-190.

Carlo, M., August, D., McLaughlin, B., Snow, C., Dressler, D., Lippman, D., Lively, T., \& White, C. (2004). Closing the gap: Addressing the vocabulary needs of English language learners in bilingual and mainstream classrooms. Reading Research Quarterly, 39, 188206.

Chafe, W. \& Danielewicz, J. (1987). Properties of Spoken and Written Language. In R. Horowitz and S.J. Samuels (Eds.), Comprehending Oral and Written Language (pp. 83113). San Diego, CA: Academic Press.

Cazden, C. B. (2002). Classroom discourse: The language of teaching and learning $\left(2^{\text {nd }} \mathrm{ed}.\right)$. Portsmouth, NH: Heinemann.

Christie, F. \& Derewianka, B. (2008). School Discourse: Learning to Write across the Years of Schooling. London: Continuum.

Cortes, V. (2004). Lexical bundles in published and student disciplinary writing: Examples from history and biology. English for Specific Purposes, 23, 397-423.

Cortes, V. (2006). Teaching lexical bundles in the disciplines: An example from a writing intensive history class. Linguistics and Education, 17, 391-406.

Coxhead, A. (2000). A New Academic Word List. TESOL Quarterly, 34, 213-238. 
Cummins, J. (1979). Cognitive/academic language proficiency, linguistic interdependence, the optimum age question and some other matters. Working Papers on Bilingualism Toronto, (19), 197-202.

Cummins, J. (1981). Bilingualism and minority-language children. Toronto, Canada: OISE Press.

Cummins, J. (2000). Language, power, and pedagogy: Bilingual children in the crossfire. Clevedon, England: Multilingual Matters.

Cummins, J. (2001). Negotiating identities: Education for empowerment in a diverse society (2nd Ed.). Los Angeles: California Association for Bilingual Education.

Cummins, J. (2008). BICS and CALP: Empirical and theoretical status of the distinction. In N. Hornberger (Ed), Encyclopedia of language and education (pp. 487-499). Dordrecht, The Netherlands: Springer.

Dale, E., \& O'Rourke, J. (1981). The living word vocabulary. Chicago: World Book-Childcraft International.

Derewianka, B. M. (2003). Grammatical metaphor in the transition to adolescence. In A. SimonVandenbergen, M. Taverniers \& L. Ravelli (Eds.), Grammatical Metaphor: Views from Systemic Functional Linguistics (pp. 185-220). Amsterdam: Benjamins.

Deshler, D. D., Palincsar, A. S., Biancarosa, G., \& Nair, M. (2007). Informed choices for struggling adolescent readers. Newark, DE: International Reading Association.

Dickinson, D. K., \& Tabors, P. O. (2002). Fostering language and literacy in classrooms and homes. Young Children, 57(2), 10-19. 
Elleman, A., Lindo, E., Morphy, P., \& Compton, D. (2009). The impact of vocabulary instruction on passage-level comprehension of school-age children: A meta-analysis. Journal of Educational Effectiveness, 2, 1-44.

Fang, Z. (2006). The language demands of science reading in middle school. International Journal of Science Education, 28, 491-520.

Fang, Z., Lamme, L., \& Pringle, R. (2010). Language and literacy in inquiry-based science classrooms, grades 3-8. Thousand Oaks, CA: Corwin.

Fang, Z. (2012). The challenges of reading disciplinary texts. In T. Jetton \& C. Shanahan (Eds.) Adolescent literacy in the academic disciplines: General principles and practical strategies (pp. 34-68). New York, NY: Guilford Press.

Fang, Z., \& Schleppegrell, M. (2008). Reading in secondary content areas: A language-based pedagogy. Ann Arbor, MI: University of Michigan Press.

Farnia, F., \& Geva, E. (2013). Growth and predictors of change in English language learners' reading comprehension. Journal of Research in Reading, 36, 389-421.

Ferguson, C. (1994). Dialect, register, and genre: Working assumptions about conventionalism. In D. Biber \& E. Finegan (Eds.), Sociolinguistic perspectives on register (pp. 15-30). New York: Oxford University Press.

Flowerdew, L. (2003). A combined corpus and systemic-functional analysis of the ProblemSolution pattern in a student and professional corpus of technical writing. TESOL Quarterly, 37, 489-511.

Geva, E. \& Farnia, F. (2012). Developmental changes in the nature of language proficiency and reading fluency paint a more complex view of reading comprehension in ELL and EL1. Reading and Writing, 25, 1819-1845. 
Gibbons, P. (1998). Classroom talk and the learning of new registers in a second language. Language and Education, 12, 99-118.Givón, T. (1992). The Grammar of Referential Coherence as Mental Processing Instructions. Linguistics, 30, 5-55.

Givón, T. (1992). The grammar of referential coherence as mental processing instructions. Linguistics, 30, 5-56.

Gough, P. B. \& Tunmer, W. E. (1986). Decoding, reading and reading disability. Remedial and Special Education, 7(1), 6-10.

Halliday, M.A.K. (2004). The Language of Science - Collected Works of M.A.K. Halliday (Vol. 5). New York: Continuum.

Halliday, M. A. K., \& Martin, J. R. (1993). Writing science: Literacy and discursive power. London: Falmer Press.

Heath, S.B. (1983). Ways with words: Language, life, and work in communities and classrooms. New York: McGraw-Hill

Heath, S. B. (2012). Words at work and play: Three decades in family and community life. Cambridge, UK: Cambridge University Press.

Hoover, W. A. \& Gough, P. B. (1990). The simple view of reading. Reading and Writing, 2, $127-160$.

Hunston, S. \& Francis, G. (2000). Pattern grammar: A corpus-driven approach to the lexical grammar of English. Amsterdam: Benjamins.

Hyland, K. (2004). Disciplinary Discourses: Social Interactions in Academic Writing. Ann Arbor, MI: University of Michigan Press.

Hyöna, J., \& Lorch, R. F. (2004). Effects of topic headings on text processing: Evidence from adult readers' eye fixation patterns. Learning and Instruction, 14, 131-152. 
Kieffer, M. J. (2009). The development of morphological awareness and vocabulary knowledge in adolescent language minority learners and their classmates. Harvard University.

Kieffer, M.J. \& Lesaux, N.K. (2007). Breaking words down to build meaning: Vocabulary, morphology, and reading comprehension in the urban classroom. The Reading Teacher, 61, 134-144.

Kieffer, M.J. \& Lesaux, N.K. (2008). The role of derivational morphological awareness in the reading comprehension of Spanish-speaking English language learners. Reading and Writing, 21, 783-804.

Kieffer, M. J., \& Lesaux, N. K. (2010). Morphing into adolescents: Active word learning for English language learners and their classmates in middle school. Journal of Adolescent \& Adult Literacy, 54, 47-56.

Kintsch, W. (2004) The Construction-Integration model of text comprehension and its implications for instruction. In R. Ruddell \& N. Unrau (Eds.), Theoretical models and processes of reading (5th ed., pp.1720-1328). Newark, DE: International Reading Association.

Krashen, S. (2012). Academic jibberish. RELC Journal: A Journal of Language Teaching and Research, 43, 283-285.

Lesaux, N. (2006). Building consensus: Future directions for research on English language learners at risk for learning difficulties. The Teachers College Record, 108, 2406-2438.

Lesaux, N. K., Kieffer, M. J., Faller, S. E., \& Kelley, J. G. (2010). The effectiveness and ease of implementation of an academic vocabulary intervention for sixth graders in urban middle schools. Reading Research Quarterly, 45, 196-228. 
LeVine, R. A., LeVine, S. E., Schnell-Anzola, B., Rowe, M. L., \& Dexter, E. (2012). Literacy and mothering: How women's schooling changes the lives of the world's children. Oxford, UK: Oxford University Press.

MacGinitie, W.H., MacGinitie, R.K., Maria, K., \& Dreyer, L.G. (2000). Gates-MacGinitie Reading Tests Forms $S \&$ T, Fourth Edition. Itasca, IL: Riverside Publishing Company.

Mancilla-Martinez, J., \& Lesaux, N. (2010). Predictors of reading comprehension for struggling readers: The case of Spanish-speaking language minority learners. Journal of Educational Psychology, 102, 701-711.

Mancilla-Martinez, J., \& Lesaux, N. (2011). The Gap Between Spanish Speakers’ Word Reading and Word Knowledge:A Longitudinal Study. Child Development, 82, 1544-1560.

Mather, N. Hammil, D. Allen E. \& Roberts, R. (2004). Test of silent word reading. Austin, TX: Pro-Ed.

Meyer, B. J. F., \& Rice, G. E. (1982). The interaction of reader strategies and the organization of text. Text, Interdisciplinary Journal for the Study of Discourse, 2, 155-192.

Meyer, B. J. F., \& Poon, L. W. (2001). Effects of structure training and signaling on recall of text. Journal of Educational Psychology, 93, 141-159.

Moje, E. B., Dillon, D. R., \& O’Brien, D. (2000). Reexamining roles of learner, text and context in secondary literacy. The Journal of Educational Research, 93, 165-180.

Mokhtari, K., \& Thompson, H. B. (2006). How problems of reading fluency and comprehension are related to difficulties in syntactic awareness skills among fifth graders. Reading Research and Instruction, 46, 73-94.

Nagy, W. \& Townsend, D. (2012). Words as tools: Learning academic vocabulary as language acquisition. Reading Research Quarterly, 47, 91-108. 
Nation, K., \& Snowling, M. J. (2000). Factors influencing syntactic awareness skills in normal readers and poor comprehenders. Applied Psycholinguistics, 21, 229-241.

Nation, K., \& Snowling, M. (2004). Beyond phonological skills: Broader language skills contribute to the development of reading. Journal of Research in Reading, 27, 342-356.

National Governors Association Center for Best Practices and Council of Chief State School Officers. (2010). Common Core State Standards. Washington, DC: Authors.

National Research Council (2010). Language Diversity, School Learning, and Closing Achievement Gaps: A Workshop Summary. M. Welch-Ross, Rapporteur. Committee on the Role of Language in School Learning: Implications for Closing the Achievement Gap. Center for Education, Division of Behavioral and Social Sciences and Education. Washington, DC: The National Academies Press. Retrieved from http://www.nap.edu/catalog.php?record_id=12907

Ninio, A. and Snow, C. (1996). Pragmatic development. Boulder, CO: Westview Press Inc.

Nippold, M.A. ( 2007). Later language development: School-aged children, adolescents, and young adults (3rd ed.). Dallas, TX: Pro-Ed.

Oakhill, J., \& Cain, K. (2000). Children's difficulties in text comprehension: Assessing causal issues. Journal of Deaf Studies and Deaf Education, 5(1), 51-59.

Ochs, E. (1993). Constructing social identity: a language socialization perspective. Research on Language and Social Interaction, 26, 287-306.

Ouellette, G. P. (2006). What's meaning got to do with it: The role of vocabulary in word reading and reading comprehension. Journal of Educational Psychology, 98, 554-566.

Perfetti, C., \& Stafura, J. (2014). Word Knowledge in Theory of Reading Comprehension. Scientific Studies of Reading, 18, 22-37. 
Phillips Galloway, E., Stude, J., \& Uccelli, P. (in press). Students' reflections on academic language. Linguistics and Education, Special Issue Academic discourse practices.

Proctor, P., Dalton, B., Uccelli, P., Biancarosa, G., Mo, E., Snow, C.E., \& Neugebauer, S. (2011). Improving comprehension online: Effects of deep vocabulary instruction with bilingual and monolingual fifth graders. Reading and Writing, 24, 517-544.

Ravid, D. \& Tolchinsky, L. (2002). Developing linguistic literacy: A comprehensive model. Journal of Child Language, 29, 419-448.

Reardon, S. F., Valentino, R. A., \& Shores, K. A. (2012). Patterns of literacy among US students. The Future of Children, 22(2), 17-37.

Rex, L . A., Thomas, E. E., \& Engel, S. (2010). Applying Toulmin: Teaching logical reasoning and argumentative writing. English Journal, 99(6), 56-62.

Sánchez, E. \& García, J.R. (2009). The relation of knowledge of textual integration devices to expository text comprehension under different assessment conditions. Reading and Writing, 22, 1081-1108.

Schleppegrell, M.J. (1998). Grammar as resource: Writing a description. Research in the Teaching of English, 32, 182-211.

Schleppegrell, M. J. (2001). Linguistic features of the language of schooling. Linguistics and Education, 12, 431-459.

Schleppegrell, M. J. (2004). The language of schooling: A functional linguistics perspective. Mahwah, NJ: Lawrence Erlbaum.

Simpson-Vlach, R. \& Ellis, N. C. (2010). An Academic Formulas List: New Methods in Phraseology Research. Applied Linguistics, 31, 487-512. 
Snow, C. E., \& Uccelli, P. (2009). The challenge of academic language. In Olson, D. R., \& N. Torrance (Eds.), The Cambridge handbook of literacy (pp. 112-133). Cambridge: Cambridge University Press.

Stahl, S. A., \& Nagy, W. E. (2006). Teaching word meanings. Mahwah, NJ: Lawrence Erlbaum. Stein, N. L., \& Glenn, C. G. (1978). An analysis of story comprehension in elementary school children. In R. Freedle (Ed.), Discourse processing: Multidisciplinary perspectives (pp. 53-120). Hillsdale, NJ: Erlbaum.

Swales, J. M. (1990). Genre analysis: English in academic and research settings. Cambridge, UK: Cambridge University Press.

Taylor, L. \& Geranpayeh, A. (2011). Assessing listening for academic purposes: Defining and operationalizing the test construct. Journal of English for Academic Purposes, 10, 89101.

Taylor, N. A., Greenberg, D., Laures-Gore, J., \& Wise, J.C. (2011). Exploring the syntactic skills of struggling adult readers. Reading and Writing, 25, 1385-1402.

Toulmin, S. (1958). The Uses of Argument. Cambridge, UK: Cambridge University Press.

Uccelli, P., Barr, C. D., Dobbs, C. L., Phillips Galloway, E., Meneses, A., \& Sánchez, E. (2014). Core academic language skills (CALS): An expanded operational construct and a novel instrument to chart school-relevant language proficiency in pre-adolescent and adolescent learners. Applied Psycholinguistics. doi:10.1017/S014271641400006X

Uccelli, P., Rosenthal, F., \& Barr, C., (2011, April). Promising connections: Play, multimodality, and more than one language in learning connectives at school. Poster presented at the Annual meeting of the American Educational Research Association, New Orleans, LA. 
Valdés, G. (2004). Between support and marginalization: The development of academic language in linguistic minority children. International Journal of Bilingual Education and Bilingualism, 7, 102-132.

Valdés, G., Capitelli, S., \& Alvarez, L. (2011). Latino Children learning English: Steps in the Journey. New York: Teachers College Press.

Paola Uccelli is Associate Professor of Education at the Harvard Graduate School of Education, Cambridge, Massachusetts, U.S.A.; e-mail: paola_uccelli@gse.harvard.edu 
Table 1. Demographic data for students in the sample $(n=218)$

$\mathrm{n}(\%)$

Gender

Female

$107(49 \%)$

Male

$111(51 \%)$

Grade
$4^{\text {th }}$
$78(36 \%)$
$5^{\text {th }}$
$58(27 \%)$
$6^{\text {th }}$
$82(37 \%)$

SES

No free/reduced lunch eligibility

$77(35 \%)$

Free/Reduced-price lunch eligible

$141(65 \%)$

$4^{\text {th }}$

46 (59\%)

$5^{\text {th }}$

$44(76 \%)$

$6^{\text {th }}$

$51(63 \%)$

\section{English proficiency designation}

English proficient (EP)

$109(50 \%)$

English Language Learners

$109(50 \%)$

ELLs

$47(22 \%)$

Former ELLS (FELL)

$62(28 \%)$

Ethnicity

Black/African American

$65(30 \%)$

White

$43(19 \%)$

Latino/Hispanic

$89(41 \%)$

Asian

$15(7 \%)$

Two or more races

$6(3 \%)$

\section{Special Education Status}

Classified as SPED

$30(14 \%)$

Total 
Table 2. Average scores for all measures by grade and English proficiency designation (EP= English proficient; FELL=Former ELL or FLEP; ELL=English Language Learner) $(n=218)^{l}$.

\begin{tabular}{|c|c|c|c|c|c|}
\hline \multirow[t]{2}{*}{ Grade } & \multicolumn{2}{|c|}{$\begin{array}{c}\text { Core Academic } \\
\text { Language } \\
\text { (CALS-I) }\end{array}$} & \multirow{2}{*}{$\begin{array}{c}\text { Reading } \\
\text { Comprehension } \\
\text { (GMRT) }\end{array}$} & \multirow{2}{*}{$\begin{array}{c}\text { Academic } \\
\text { Vocabulary } \\
(V A T)\end{array}$} & \multirow{2}{*}{$\begin{array}{c}\text { Word Reading } \\
\text { Fluency } \\
\text { (TOSWRF) } \\
\text { Mean (s.d.) }\end{array}$} \\
\hline & $n$ & Mean (s.d.) & & & \\
\hline $4^{\text {th }}$ grade $(E P)$ & 40 & $.22(1.69)$ & $504.3(42.83)$ & $34.6(5.41)$ & $99.93(30.23)$ \\
\hline $4^{\text {th }}$ grade (FELL) & 18 & $0.58(1.61)$ & $514.72(40.38)$ & $33.50(5.70)$ & $110.67(29.25)$ \\
\hline $4^{\text {th }}$ grade (ELL) & 20 & $-0.85(1.06)$ & $469(36.13)$ & $28.9(4.64)$ & $83.05(28.51)$ \\
\hline $4^{\text {th }}$ grade (Total) & 78 & $0.03(1.61)$ & $497.65(43.77)$ & $32.88(5.75)$ & $98.08(30.82)$ \\
\hline $5^{\text {th }}$ grade $(E P)$ & 28 & $-0.07(1.33)$ & $490.11(42.45)$ & $34.14(4.56)$ & $87.57(32.11)$ \\
\hline $5^{\text {th }}$ grade $(F E L L)$ & 16 & $0.89(0.56)$ & 508.88 (23.59) & $35.94(4.36)$ & $108.75(16.34)$ \\
\hline $5^{\text {th }}$ grade $(E L L)$ & 14 & $-0.52(1.03)$ & $466.64(25.36)$ & $30.93(5.78)$ & $87.36(16.40)$ \\
\hline $5^{\text {th }}$ grade (Total) & 58 & $0.09(1.2)$ & $486.62(37.16)$ & $33.86(5.08)$ & $93.36(26.68)$ \\
\hline $6^{\text {th }}$ grade $(E P)$ & 41 & $1.02(1.60)$ & $516.51(39.28)$ & $36.83(4.53)$ & $118.8(27.55)$ \\
\hline $6^{\text {th }}$ grade $(F E L L)$ & 28 & $0.65(1.87)$ & $508.21(40.18)$ & $36.78(3.18)$ & $116.54(27.12)$ \\
\hline$\sigma^{\text {th }}$ grade $(E L L)$ & 13 & $-0.22(.90)$ & $482.15(34.63)$ & $34.23(5.17)$ & $97.92(24.20)$ \\
\hline $6^{\text {th }}$ grade (Total) & 82 & $0.71(1.67)$ & $508.23(40.27)$ & $36.40(4.29)$ & $114.72(27.60)$ \\
\hline Total sample & 218 & $.30(1.6)$ & $499.50(41.28)$ & $34.47(5.27)$ & $103.08(29.90)$ \\
\hline
\end{tabular}

${ }^{1}$ As a reference point, we offer here the corresponding mean raw score and percent correct scores by grade for the CALS-I IRT factors scores reported in Table 2. Fourth grade: mean raw score $=18.79 ; \mathrm{SD}=9.98$; mean percent correct score $=.52, \mathrm{SD}=.28$. Fifth grade: mean raw score $=19.67, \mathrm{SD}=7.73$; mean percent correct score $=.55$, $\mathrm{SD}=.21$. Sixth grade: mean raw score $=22.54, \mathrm{SD}=9.49$; mean percent correct score $=.63, \mathrm{SD}=.26$.). 
Table 3. Correlation table for all measures and demographic variables included in models $(n=218)$.

\begin{tabular}{|c|c|c|c|c|c|c|c|}
\hline & 1 & 2 & 3 & 4 & 5 & 6 & 7 \\
\hline \multicolumn{8}{|l|}{ 1. Core Academic Language (CALS-I) } \\
\hline 2. Reading Comprehension (GMRT) & $0.73 * * *$ & & & & & & \\
\hline 3. Word Reading Fluency (TOSWRF) & $0.60 * * *$ & $0.59 * * *$ & & & & & \\
\hline 4. Academic Vocabulary (VAT) & $0.64 * * *$ & $0.59 * * *$ & $0.54 * * *$ & & & & \\
\hline 5. Gender & 0.13 & 0.07 & $0.15^{*}$ & 0.06 & & & \\
\hline 6. English Proficiency Designation & $-0.22 * *$ & $-0.24 * *$ & -0.16 & $-0.27 * * *$ & -0.01 & & \\
\hline 7. SES (Free/Reduced Lunch Status) & $-0.28 * * *$ & $-0.24 * *$ & $-0.23 * * *$ & $-0.27 * * *$ & -0.04 & $0.21 *$ & \\
\hline 8. Grade & $0.19 *$ & 0.11 & $0.24 * *$ & $0.29 * * *$ & 0.03 & -0.05 & 0.03 \\
\hline
\end{tabular}

$$
* \mathrm{p}<0.05 * * \mathrm{p}<0.001 * * * \mathrm{p}<0.0001
$$


Table 4. Regression model to predict reading comprehension (Gates-MacGinitie Reading Test ESS scores) based on CALS-I scores, controlling for word reading fluency, academic vocabulary scores, English proficiency designation, and SES $(n=218)$

\begin{tabular}{|c|c|c|c|c|c|}
\hline & Model 1 & Model 2 & Model 3 & Model 4 & Model 5 \\
\hline Grade & $0.10(3.14)$ & $0.11(3.01)$ & $-0.02(2.68)$ & $-0.09(2.55)$ & $-.08(2.24)$ \\
\hline \multicolumn{6}{|l|}{ English Proficiency } \\
\hline Designation & $-0.26(3.38) * * *$ & $-0.21(3.75)^{* *}$ & $-0.16(2.91) * *$ & $-0.10(2.76) \sim$ & $-0.09(2.43)$ \\
\hline \multicolumn{6}{|l|}{ SES } \\
\hline (Free/Reduced Lunch Status) & & $-0.21(5.86) * *$ & $-0.10(5.92) \sim$ & $-0.05(4.63)$ & $-0.01(4.10)$ \\
\hline $\begin{array}{l}\text { Word Reading Fluency } \\
\quad(T O S W R F)\end{array}$ & & & $.54(.08) * * *$ & $0.38(0.08)^{* * *}$ & $0.10(0.08) * *$ \\
\hline $\begin{array}{l}\text { Academic Vocabulary } \\
\qquad(V A T)\end{array}$ & & & & $0.40(0.49)^{* * *}$ & $0.16(0.48)^{* *}$ \\
\hline $\begin{array}{l}\text { Core Academic Language } \\
\quad(C A L S-I)\end{array}$ & & & & & $0.50(1.67) * * *$ \\
\hline Observations & 218 & 218 & 218 & 218 & 218 \\
\hline Variance Explained () & 0.08 & 0.12 & 0.38 & 0.47 & 0.59 \\
\hline Change in & & $0.04^{* *}$ & $0.26 * * *$ & $0.09 * * *$ & $0.12 * * *$ \\
\hline
\end{tabular}

$\sim \mathrm{p}<.01, * \mathrm{p}<.05, * * \mathrm{p}<.01, * * * \mathrm{p}<.0001$ 
Figure 1. Mean percent correct CALS-I scores by SES and English proficiency designation.

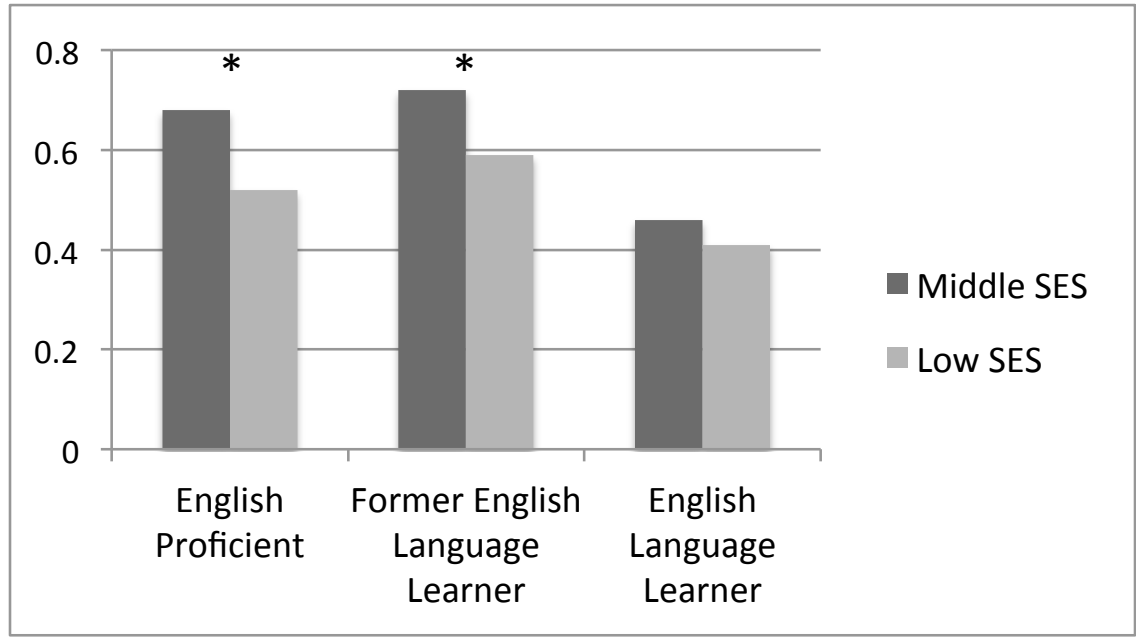


Figure 2. A visual representation of the interrelated subset of skills comprised in the Core Academic Language Skills (CALS) construct.

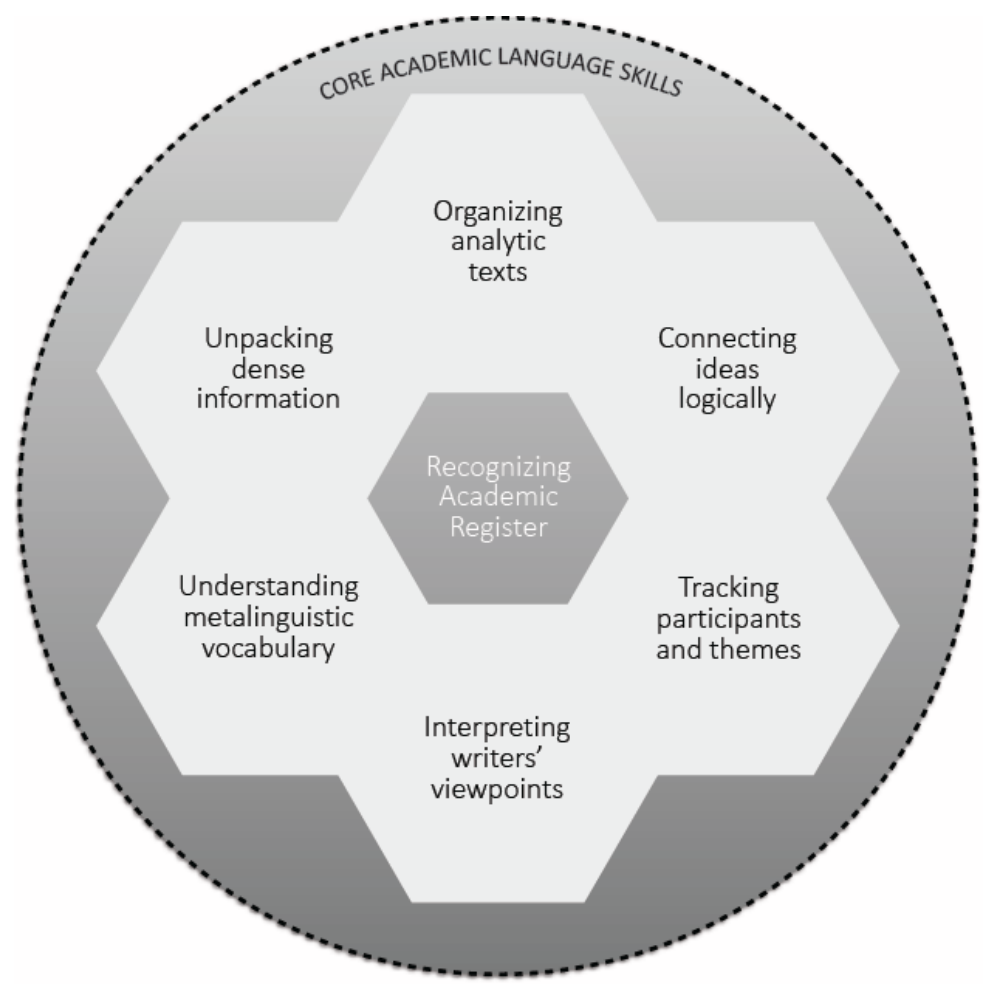




\section{Appendix 1}

Core Academic Language Skills Instrument (CALS-I): Description of tasks (Adapted from Uccelli et al., 2014)

\begin{tabular}{|c|c|c|c|}
\hline CALS-I Tasks & $\begin{array}{c}\text { Skills } \\
\text { measured }\end{array}$ & $\begin{array}{c}\text { Sample } \\
\text { items }\end{array}$ & $\begin{array}{c}\text { Sources } \\
\text { for research-based design }\end{array}$ \\
\hline $\begin{array}{l}\text { Unpacking } \\
\text { complex words } \\
\text { Selected items } \\
\text { from } \\
\text { Kieffer's (2009) } \\
\text { adaptation of } \\
\text { Carlisle (2000) }\end{array}$ & $\begin{array}{l}\text { Skill in decomposing } \\
\text { morphologically-derived } \\
\text { words }\end{array}$ & $\begin{array}{l}\text { SAMPLE ITEM: } \\
\text { Administrator reads a set of } \\
\text { morphologically derived words followed } \\
\text { by an incomplete sentence and students are } \\
\text { asked to complete the sentence by } \\
\text { extracting the base from the derived word: } \\
\text { ethnicity. The city had many_ groups. } \\
\text { Additional examples of morphologically } \\
\text { complex words tested: invasion, } \\
\text { durability, contribution }\end{array}$ & $\begin{array}{l}\text { This task consists of a subset of items from } \\
\text { Kieffer's Morphological Decomposition Task, } \\
\text { an adaptation of Carlisle's (2000) measure } \\
\text { (Kieffer \& Lesaux, 2007, 2008, 2010). } \\
\text { Responses were scored as correct or incorrect } \\
\text { following Kieffer's (2009) scoring protocol. } \\
\text { Correct responses included phonetically } \\
\text { logical versions of the word (e.g., 'popular' } \\
\text { and 'populer' were scored as correct). }\end{array}$ \\
\hline $\begin{array}{l}\text { Unpacking } \\
\text { complex sentences } \\
\text { Selected and } \\
\text { adapted items from } \\
\text { the TROG-2 } \\
\text { (Bishop, 2003) }\end{array}$ & $\begin{array}{l}\text { Skill in } \\
\text { understanding complex } \\
\text { syntax }\end{array}$ & $\begin{array}{l}\text { SAMPLE ITEM: } \\
\text { Administrator reads a sentence and } \\
\text { students are asked to select the picture that } \\
\text { corresponds to the target sentence. Four } \\
\text { pictures are presented, three of which } \\
\text { depict sentences altered by a grammatical } \\
\text { element, e.g., } \\
\text { The sheep the girl looks at is running. } \\
\text { Additional examples of syntactic structures } \\
\text { tested: neither...nor construction, relative } \\
\text {. . . . }\end{array}$ & $\begin{array}{l}\text { This task consists of a selective adaptation of } \\
\text { the Test of Receptive Grammar-2 (TROG-2) } \\
\text { (Bishop, 2003), a test suitable for ages } 4 \text { to } \\
\text { young adulthood. From a total of } 80 \text { items, } \\
10 \text { were selected to assess five constructs } \\
\text { prevalent in academic texts (e.g., relative } \\
\text { clause in object, center-embedded relative } \\
\text { clause). Contrary to the TROG-2, this } \\
\text { adapted version was only group } \\
\text { administered. }\end{array}$ \\
\hline
\end{tabular}




\begin{tabular}{|c|c|c|c|}
\hline $\begin{array}{l}\text { Connecting } \\
\text { ideas logically }\end{array}$ & $\begin{array}{l}\text { Skills in understanding } \\
\text { school-relevant } \\
\text { connectives and discourse } \\
\text { markers }\end{array}$ & $\begin{array}{l}\text { SAMPLE ITEM A: } \\
\text { Students are asked to select the missing } \\
\text { marker from among four options: } \\
\text { Kim was sick_she stayed home and } \\
\text { did not go to school } \\
\text { Options: } \text { OTHERWISE, YET, IN CONTRAST } \\
\text { AND AS RESULT } \\
\text { SAMPLE ITEM B: Students are asked to } \\
\text { select the best continuation for an } \\
\text { incomplete sentence, from among three } \\
\text { options: } \\
\text { Most teachers think that homework is } \\
\text { important. ON THE OTHER HAND ... } \\
\text { Additional examples of markers tested: } \\
\text { consequently, nevertheless, in conclusion. }\end{array}$ & $\begin{array}{l}\text { The development of this task was informed by } \\
\text { prior researcher-designed assessments (Uccelli, } \\
\text { Rosenthal, \& Barr, 2011; Sánchez \& García, } \\
\text { 2009). The selection of frequent academic } \\
\text { markers at different levels of difficulty was } \\
\text { informed by databases of students' word } \\
\text { knowledge (LWV, Dale \& O'Rourke, 1981), } \\
\text { word frequency in school texts (Zeno et al., } \\
\text { 1995) and academic lexical bundles derived } \\
\text { from corpus analyses (Biber, Conrad \& Cortes } \\
\text { 2004; Cortes, 2004, 2006; Simpson-Vlach \& } \\
\text { Ellis, 2010). }\end{array}$ \\
\hline $\begin{array}{l}\text { Tracking } \\
\text { participants } \\
\text { and themes }\end{array}$ & $\begin{array}{l}\text { Skill in anaphoric } \\
\text { resolution }\end{array}$ & $\begin{array}{l}\text { SAMPLE ITEM: } \\
\text { Students are asked to match the underlined } \\
\text { text with its antecedent by selecting among } \\
\text { three options: } \\
\text { China resisted the move for change. In } 1989 \\
\text { students protested to demand changes, but } \\
\text { the army opposed these changes. Troops } \\
\text { were sent to stop the movement. } \\
\text { Additional passages were similar in length } \\
\text { and included concrete and abstract } \\
\text { referents. }\end{array}$ & $\begin{array}{l}\text { The design of this task was informed by a } \\
\text { prior researcher-designed assessment used in } \\
\text { studies of middle-school students' reading } \\
\text { comprehension (Sánchez \& García, 2009). }\end{array}$ \\
\hline $\begin{array}{l}\text { Organizing } \\
\text { argumentative } \\
\text { texts }\end{array}$ & $\begin{array}{l}\text { Skill in argumentative text } \\
\text { organization }\end{array}$ & $\begin{array}{l}\text { Students are asked to order six fragments of } \\
\text { a brief essay (introduced by conventional } \\
\text { markers: 'in my opinion,' 'one reason' 'in }\end{array}$ & $\begin{array}{l}\text { The design of this task was informed by the } \\
\text { story anagram task used by Stein \& Glenn } \\
\text { (1978), and by Cain, Oakhill and colleagues }\end{array}$ \\
\hline
\end{tabular}




\begin{tabular}{|l|l|l|l|}
\hline & & $\begin{array}{l}\text { conclusion') in order to display a } \\
\text { conventional argumentative text structure. }\end{array}$ & $\begin{array}{l}\text { in their reading comprehension studies (Cain } \\
\text { \& Oakhill, 2006). }\end{array}$ \\
\hline $\begin{array}{l}\text { Recognizing } \\
\text { academic } \\
\text { register }\end{array}$ & $\begin{array}{l}\text { Skill in identifying } \\
\text { academic definitions }\end{array}$ & $\begin{array}{l}\text { Students are asked to select the most } \\
\text { academic definition, from a set of three } \\
\text { definitions of the same familiar word. }\end{array}$ & $\begin{array}{l}\text { This task was inspired by research on } \\
\text { children's register awareness. However, the } \\
\text { specific design was not modeled after any } \\
\text { prior research (Andersen, 1996; Gibbons, } \\
\text { 1998). }\end{array}$ \\
\hline
\end{tabular}

